\title{
CONSIDERAÇÕES SOBRE O TEMPO E SUAS CONTINGÊNCIAS EM UMA CLÍNICA-ESCOLA
}

\author{
Oswaldo França Neto*
}

\section{Resumo}

A partir de dificuldades concernentes ao tempo clínico observadas nos ambulatórios de instituições de ensino voltados para o atendimento de população de baixa renda, este texto tenta problematizar o que poderia vir a ser uma apreensão contemporânea da noção de tempo. De uma concepção historicizante, eminentemente simbólica e baseada na sucessão, exploram-se aqui outras possibilidades, baseadas agora na conexão e na associação, nas quais uma abordagem topológica do tempo mostrar-se-ia mais adequada.

Palavras-chave: tempo; temporalidades; tempo lógico; clínica-escola.

\section{AbSTRaCt}

CONSIDERATIONS ON TIME AND ITS CONTINGENCIES WITHIN A UNIVERSITY CLINIC

Considering the difficulties regarding clinical time observed in emergency/waiting rooms in educational institutions dealing with the treatment of the lower-income population, this article aims to lay out the problems that may develop into a contemporary apprehension of the notion of time. Looking from an historical approach that is both eminently symbolic and based on succession, we explore some other possibilities based on connection and association, where a topological approach regarding time may be more adequate.

Keywords: time; temporalities; logical time; clinical institution.

O tempo é uma linha contínua, sem escansões, ou é discreto, dividido em partes dispostas em sequência?

Quando vamos para o campo da topologia e passamos a lidar com o espaço, este, em si mesmo, não encerra a dimensão de profundidade, a famosa terceira

* Psicanalista e Professor Adjunto do Programa de Pós-graduação do Departamento de Psicologia da Universidade Federal de Minas Gerais (UFMG). 
dimensão, na qual situaríamos a temporalidade. Para que esta se coloque é necessário que se mergulhe no espaço e se movimente, sendo a partir desses movimentos ao longo do tempo que vai passar a "existir um antes e um depois e, por extensão, um na frente e um atrás" (Granon-Lafont, 1990: 13). Um bom objeto topológico para apreendermos essa questão é a Banda de Moebius. Se utilizarmos a metáfora da formiga andando ao longo de sua superfície, a medida do que a formiga percebe como profundidade, no horizonte em que a banda revira torcendo-se sobre si mesma, será o tempo que a formiga levará para alcançar a torção, ponto este que na verdade ela jamais alcançará, pois uma vez que supostamente o atinja um novo horizonte irá se apresentar como terceira dimensão, como profundidade.

A noção de profundidade ou horizonte, em termos topológicos, é dada, assim, pelo tempo necessário para alcançá-la. Vemos aqui a importância do limite ou da escansão temporal na estruturação do espaço. O psicótico, por exemplo, é alguém sobre o qual dizemos "ser sem limites, ou seja, sem dimensão temporal" (Granon-Lafont, 1990: 14). Existe nele uma precariedade no estabelecimento de escansões no real que o invade.

Voltando à questão com a qual iniciamos este texto, o tempo da consciência, com certeza, é discreto, marcado pelas escansões que o nosso sistema perceptual reconhece. Contemporaneamente, ele está, de forma majoritária, dominado pelo relógio e pela folhinha, contado em segundos, minutos, horas, dias, semanas, meses, anos. Ele tem passado, presente e futuro, e podemos fazer dele uma agenda - hoje em dia quem é que consegue viver sem estar minimamente referenciado a uma agenda, a uma temporalidade?

Robson Crusoé, quando se viu náufrago, como estratégia para preservar-se na cultura que era a sua, manteve-se em sua temporalidade, marcando sobre uma superfície os dias da semana e estabelecendo rotinas cadenciadas por um ritmo estruturante.

Nós somos seres de linguagem. A rigor, somos apenas linguagem (entendendo aí suas três dimensões: real, simbólica e imaginária). O que nos diferencia dos animais é o fato de sermos falantes, atravessados que somos pela linguagem, a ponto de podermos propor que aquilo que nos define não é pensável fora dos avatares da linguagem. Como já sabia Descartes ([1649] 1983), nossos pensamentos e aquilo que concebemos como sendo nosso corpo são coisas distintas. Nós falamos "tenho um corpo" e não "sou um corpo". Mas, se eu não sou um corpo, o que sou "eu"? Alma? Descartes, assim como a religião nomearam dessa forma uma suposta substância na qual encontraríamos nossos pensamentos. Mas, para a psicanálise, somos apenas linguagem. Não é de uma ontologia ou de uma 
substância que nos fala Freud. O inconsciente não tem estatuto ontológico (Lacan, [1963-1964] 1985), assim como o ser da filosofia (ou da física clássica) não se confunde com o real lacaniano (Badiou, 1999).

O que constitui o tempo é a linguagem. Antes dela, o tempo não existia. Para os animais, ao que tudo indica, não existe passado, presente ou futuro, mas um puro aqui e agora, que não se destaca de sua experiência corporal. $\mathrm{O}$ animal não se percebe como possuindo um corpo, exterior a ele. A rigor, ao que parece, o animal nem chega a se contar como mais um em relação à natureza.

O tempo, então, estrutura-se como linguagem. Esta constitui o tempo, seriando-o em vários pequenos fragmentos que podem ser colocados um na frente do outro, constituindo o passado, o presente e o futuro.

Lacan, nos anos 50, lançando mão de um simbólico poderoso, identifica no inconsciente a própria história do sujeito:

O que ensinamos o sujeito a reconhecer como seu inconsciente é sua história ou seja, nós o ajudamos a perfazer a historicização atual dos fatos que já determinaram em sua existência um certo número de "reviravoltas" históricas. [...]. Assim, toda fixação numa pretensa fase instintual é, antes de mais nada, um estigma histórico: página de vergonha que se esquece ou se anula, ou página de glória que constrange (Lacan, [1966] 1998: 263).

Seria o período que aprendemos a chamar por primeiro ensino, momento em que Lacan conceberia "que o sujeito se realizava uma vez tendo atingido reconhecimento da ordem simbólica” (Garcia, 2002: 313). Nesse momento, a importância dada à historicização, com seu passado, presente e futuro (cadeia significante), parece demonstrar uma articulação entre a Tiquê (encontro fortuito, contingente) e a Autômaton (regra, norma, modelo): a prevalência caberia à segunda. Na década seguinte, no Seminário XI, em capítulo intitulado precisamente "Tiquê e Autômaton", deslocando-se de Aristóteles para Demócrito, um pré-socrático, Lacan parece situar-se em posição diferente: "Se o desenvolvimento se anima inteiramente pelo acidente, pelo tropeço da tiquê, é na medida em que a tiquê nos traz de volta ao mesmo ponto em que a filosofia pré-socrática procurava motivar o próprio mundo" (Lacan, [1963-1964] 1985: 64). Vemos aqui, em 1964, uma prevalência do acidente, do tropeço, em detrimento da sequência ou da história. A tiquê nos retira da linha da história, aquela que confere sentido aos acontecimentos inserindo-os em uma sequência e em uma teleologia. Se formos pensar sob a égide da tiquê, pensaremos em um tempo neutro, sem sentido, no qual os acontecimentos deixam de ter um final natural determinado pela linha diacrônica 
da história. De sequência linear passamos para um presente maciço, onipresente, que fabrica a cada instante o passado e o futuro de que necessita. Slavoj Zizek (2000), comentando os trabalhos do cineasta polonês Krzystof Kieslowski, nos fala dessa perda contemporânea da linearidade, explorada pelas artes e mesmo pelas ciências:

Uma nova "experiência de vida" parece estar hoje no ar, a percepção de uma nova vida faz explodir a forma da narrativa linear centrada, que apresenta a vida como um fluxo multiforme; até no domínio das ciências "duras" (física quântica e sua interpretação da Realidade Múltipla; neo-darwinismo) parecemos obcecados com a ideia das oportunidades perdidas da vida e pelas versōes alternativas da realidade (Zizek, 2000: s/p; tradução nossa).

Zizek (2000) nos remete à possibilidade de universos paralelos, versões outras que se dariam a partir de escolhas arbitrárias, "conferindo à nossa realidade o estatuto de extrema fragilidade e contingência” (Zizek, 2000: s/p; tradução nossa). No filme de 1991 A dupla vida de Verônica de Kieslowski, encontramos vidas paralelas, múltiplas, marcadas pela contingência de uma escolha. Este cineasta faz valer a tiquê em disjunção da sucessão linear da história. Essa explosão de universos tem se mostrado uma realidade também em outros campos bem próximos ao nosso dia-a-dia, como por exemplo no espaço virtual do mundo cibernético.

\section{O CONTÍNUO E O INFINITO}

Alain Badiou (1996), em O ser e o evento, fala do "problema do contínuo" (Badiou, 1996: 14), impasse intrínseco do pensamento matemático, em que se diria o impossível próprio que funda esse domínio. Esse obstáculo, mais do que ser algo restrito ao campo da matemática, poderíamos dizê-lo, representa o impasse do próprio pensamento. Para driblá-lo, fragmentamos, seriamos o contínuo, tornando-o discreto, restando dele apenas o que inelutavelmente insiste em escapar a essa imposta sucessão de escansões. Fracionar o contínuo foi a forma que encontramos para regrar o gozo temporal, possibilitando, nos intervalos, a inscrição de um sujeito. E é nos impasses desse regramento que o trabalho analítico se processa, visando, com seu ato, a inscrição do real, ou a sustentação de sua presença faltante, na marcação de um contínuo impossível de se inscrever.

O contínuo, na teoria matemática dos conjuntos, inscreve-se como infinito. Daí a impossibilidade de essa teoria lidar com as questôes do infinito, dificuldade esta pelo menos parcialmente superada graças a uma manobra astuciosa do ma- 
temático alemão Georg Cantor (1845-1918) que, ao forçar sua nomeação arbitrária ("Aleph”), possibilitou dele uma formalização aplicável.

O infinito só pode ser vivenciado se constrangido pela escansão. Podemos dizer que aceitar a própria finitude, ou seja, aceitar ter nascido e ser mortal, é a única forma de "ultrapassar a angústia do tempo limitado" (Lavendhomme, 2001: 34), possibilitando experienciar seu tempo não como finito, mas, ao contrário, como homeomorfo à reta infinita. O obsessivo, por exemplo, padece de procrastinação, de prolongamento ao infinito do momento de confronto com o Outro. Submeter-se à castração implica viabilizar a possibilidade de vivenciar a eternidade de seu próprio limite, poder experienciar a infinitude de sua finitude. Segundo Jean-Luc Nancy (2003), a psicanálise não é uma terapêutica ou uma proposição sobre a doença, mas uma proposição sobre a finitude. Freud, com o inconsciente, teria estabelecido a marca finita da consciência. $\mathrm{O}$ inconsciente significaria o "fim da consciência", ou o "fim da significação" (Nancy, 2003: 146). Significa a natureza nela mesma finita da consciência, sua finitude eterna. $\mathrm{O}$ inconsciente como a dis-cursividade do desejo, que se reenvia de significante em significante, mostrando com isso sua finitude, ou seja, o limite que o impede de chegar a seus fins. A finitude da marca que instaura o sujeito faz com que este se desloque infinitamente. Uma finitude, segundo Nancy, marcada pelo inacabamento e que, por se dar localmente, apresenta-se essencialmente como deslocamento. Talvez uma forma de expressar a passagem da impotência para a impossibilidade (objetivo de toda análise $)^{1}$, ou seja, aceitar a finitude inacabada, e portanto eterna, da própria existência.

Mas qual será a temporalidade do inconsciente? O inconsciente é estruturado como uma linguagem, dizia Lacan. Sendo assim, ele também tem sua temporalidade. Mas tratar-se-ia de uma temporalidade similar àquela da consciência, marcada pela sucessão progressiva do relógio, de forma que possamos identificar um fragmento passado, um presente, e um outro por vir?

$\mathrm{Na}$ "Carta 52", Freud ([1896] 1977) fala que no inconsciente as inscrições ou marcas se dão por relação, por conectividade, e não por sucessão. Uma imagem está relacionada a outra não necessariamente porque façam parte de uma mesma sequência cronológica. Elas estão conectadas, por exemplo, por terem a mesma cor, o mesmo cheiro, o mesmo som, produzirem a mesma dor... As possibilidades de conexão são infinitas, mas, definitivamente, elas não estão necessariamente cativas à sequência do relógio. $O$ passado não é algo que já aconteceu, assim como o futuro não se reduz ao que ainda está por vir. No aqui e agora disso que chamamos inconsciente, presente, passado e futuro estão juntos, em um grande presente alargado, que tudo engloba. No inconsciente, minha existência presente 
não se distingue do passado e do futuro. Não existe um dentro e um fora, mas um fora-dentro, onde um continua-se no outro e, ao transformar-se no outro, nem por isso desloca para o passado o que teria sido antes.

Mas apesar de o relógio não fazer sentido para o inconsciente, Freud não deixa de postular ali também uma temporalidade. Uma temporalidade, porém, esquisita, subversiva. Existiria inicialmente uma fixação (Fixierung), que na verdade nem sabemos se realmente existiu, posto que localizada em um tempo mítico, uma postulação teórica para que o aqui e agora faça sentido. Depois, em um tempo posterior a essa hipotética marca primeva, algo aconteceria - recalque (Verdrängung) propriamente dito - contextualizando esse traço mítico, inscrevendo-o como necessariamente fora da consciência e constituindo assim uma subjetividade partida, clivada. Esse segundo tempo, na verdade, criaria retroativamente o primeiro, como uma referência lógica necessária para que o acontecimento clivante possa adquirir seu efeito traumático e exercer sua função. Uma temporalidade lógica, dirá Lacan.

Freud não para por aí, propondo a seguir um terceiro tempo, que ele nomeará por retorno do recalcado (Nachverdrängung), no qual essa inscrição primeira retornaria, produzindo-se como efeito na consciência. Estariam contemplados aqui os sintomas, os lapsos, os atos falhos e os sonhos. Mas Lacan, reafirmando o aspecto subversivo da temporalidade freudiana, afirma que "o recalque e a volta do recalcado são a mesma coisa" (Lacan, [1953-1954] 1986: 222). Ou seja, para Lacan, o mais antigo no tempo se confunde com o aqui e agora da consciência. $\mathrm{Na}$ verdade, esse passado e esse presente não apenas se confundem, mas, para Lacan, são a mesma coisa - o que é mais antigo no tempo é também o mais recente. $\mathrm{O}$ antigo, assim como o recente, são recriados a cada instante. $\mathrm{O}$ passado faz parte do presente, não propriamente por determiná-lo por meio de uma causalidade simplista, mas porque se constituem juntos, no mesmo ato, em uma relação de dupla determinação.

Seguindo à risca a afirmação de que o recalque e o retorno do recalcado são a mesma coisa, podemos dizer que a criação do psíquico, que se dá em ato, não é algo que se processe um dia e, a partir de então, a estrutura estará totalizada. Esse ato, o momento da criação, é algo que se repete ininterruptamente. $\mathrm{O}$ retorno do recalcado tem valor estruturante, propiciando, como o próprio ato de um recalque miticamente anterior, a reinstauração do novo.

A partir do momento em que podemos falar do aparelho psíquico como existindo, não nos é possível mais identificar aquela primeira vez que teria sido primordial. Toda manifestação da consciência é reflexo de um ato que acabou de se processar, tendo como efeito a criação instantânea e eterna do aparelho psíqui- 
co. A prática analítica é dessa ordem: ela reorganiza passado e futuro segundo o momento de sua asserção, e em função de uma enunciação apenas entre a retrogressão e a progressão. Se a classificação, a separação em partes ou conjuntos bem ordenados, encontra-se na lógica do tempo progressivo (a psicologia da consciência e a psiquiatria apresentam-se na lógica da progressão), a psicanálise aciona um caráter de après-coup (Nachträglich) retroativo. $\mathrm{O}$ ato analítico não saberia ser predicado, assim como o real não se deixa predicar, não se permitindo cernir por qualquer classificação. $\mathrm{O}$ ato analítico, ao efetuar-se, cliva e projeta o improjetável.

Coloca-se então a questão: qual a duração de uma análise? É errado estabelecer datas? É errado não estabelecer?

\section{As TEMPORALIDADES DE UMA CLÍNICA-ESCOLA}

Existe uma análise, descrita por Freud ([1893] 1974), que durou o tempo de um passeio pelo campo. Lacan, em confronto com a IPA, e por isso mesmo excomungado por ela, fala de um tempo lógico, distinto do relógio e das marcações da folhinha. Seria a temporalidade do inconsciente, diria ele, que não se submete ao tempo da razão, da linearidade diacrônica da consciência.

$\mathrm{O}$ real (e talvez possamos dizer também o tempo contínuo, aquele que remete ao infinito) escorre entre os dedos. Por mais que tentemos apreendê-lo, codificálo, segmentá-lo (e não temos outra alternativa a não ser mantermo-nos nessa tentativa), está sempre escapando, escorrendo, mostrando-se como falta, falta a ser, falta a estar.

Essa questão é especialmente premente nas clínicas vinculadas a instituições de ensino. Quando, em uma clínica-escola, um paciente começa um processo terapêutico, temos em mente que boa parte deles já viria sabendo que provavelmente seu terapeuta será um aluno, e acreditamos que muitos já possuiriam a expectativa de que seu tempo de terapia estaria restrito a um, ou talvez dois semestres letivos. Os efeitos advindos sobre o paciente desse saber que presumimos neles frequentemente preocupa os profissionais mais engajados. Mas será que estamos em condições de bem avaliar os alcances dessa questão? O tempo do público alvo da clínica-escola seria similar, ou teria conotaçôes similares ao tempo institucional?

A instituição está bem inserida no sistema e nas suas marcações. Mas, em alusão ao geógrafo Milton Santos ([1989] 2001), poderíamos pensar que o tempo dos pobres (onde colocaríamos a maior parte dos pacientes que nos procuram nessas instituições) aparentemente seja diferente do nosso. O tempo deles apresenta-se, ao que parece, como um tempo lento. Seria essa lentidão a única arma de 
que disporiam. Privados de incitações e indicações provenientes de um universo que lhes é estranho, para eles o tempo (livre ou outro) não vem cadenciado pelo ritmo do tempo marcado. Eles só conhecem o tempo sem marcas. $\mathrm{O}$ morador de rua, por exemplo, dispõe de um tempo amplo para prestar atenção em detalhes que nos escapam. Eles agem como se dispusessem de todo o tempo do mundo (ver o interessante filme-documentário $\grave{A}$ margem da imagem (2003) de Evaldo Mocarzel e Cecília Loschiavo, mostrando o dia-a-dia de um grupo de moradores de rua em São Paulo). Basta olhar também o tempo lento da empregada quando seus patrões chegam apressados em casa para o almoço durante a semana, motivo de conflitos frequentes entre as donas de casa atarefadas e suas lentas serviçais.

Esse tempo desmarcado dos não-incluídos ganha materialidade própria, na qual se inscrevem novos traços agora frutos da contingência, dos acontecidos na duração temporal de cada um. Trata-se de um tempo próprio, com uma cadência estranha ao tempo hierárquico hegemônico. Essa diferença com frequência nos leva a identificar nesse tempo anacrônico, e nessa população específica, um suposto déficit a ser corrigido. O professor Célio Garcia, ao trabalhar o filmedocumentário Estamira ${ }^{2}$ do diretor Marcos Prado em uma série de palestras que vem fazendo nos serviços substitutivos de saúde mental em Belo Horizonte, Minas Gerais, defende a utilização do termo "carência” em contraposição, por exemplo, a "déficit". A carência não é algo a ser corrigido, mas é solo para a criatividade, para a construção de um território onde a loucura (de Estamira, no filme em questão) possa ser experienciada não como uma cronificação (termo psiquiátrico estagnante), mas como "duração" (termo proposto por Garcia). O termo déficit nos lembra a forma com que alguns psicoterapeutas apressados identificaram na "atemporalidade" do inconsciente uma ausência de tempo. Freud, como vimos acima, não eliminou o tempo do inconsciente. Apenas desmarcou-o, libertandoo da sucessão cronológica. O tempo do inconsciente é determinado pela conectividade e não pela sucessão, o que o torna estranho à concepção evolucionista. Não que a psicanálise deixe de pensar em certa progressão do trabalho analítico, mas trata-se antes de um percurso, de um movimento, no qual os passos envolvidos estariam desmarcados. Não é possível prever antes, ou estipular valorações para os fatos que acontecerão a seguir, o que não nos impede de buscar certo tipo de movimento. Se a psiquiatria pode propor-se quantificar os resultados obtidos, essa possibilidade é estranha ao movimento psicanalítico.

A sensação do tempo, então, é flexível, mudando inclusive de acordo com a cultura ou a época de cada sujeito. O tempo hoje não é o mesmo que era há dois séculos, provavelmente não é o mesmo de vinte anos atrás. Transformações ocorreram e continuam a acontecer. Quando, no século XVII, Christiam Huygens 
(1629-1695) estabeleceu a teoria do pêndulo e a utilizou como reguladora no movimento dos relógios, o tempo provavelmente ainda não era marcado pela força da temporalidade hierarquizante que nos fez progressivamente, nos séculos que se seguiram, pessoas submetidas a tempos marcados. Marcações estas que, com a aceleração do capitalismo, foram tornando o tempo pequeno, espremido, dando-nos a impressão de estarmos entrando em uma espiral concêntrica de aceleração progressiva que parece ser infinita. Nós estamos na era da internet, dos aviōes supersônicos, da vida on-line. A (pós)modernidade se nos apresenta como se fosse um trem-bala, vendendo-nos a imagem de que existiriam aqueles que teriam conseguido comprar seu bilhete, outros que estariam definitivamente fora, excluídos da viagem, e por fim um terceiro grupo, composto por aqueles que estariam em suspensão, pendurados na janela, esforçando-se por entrar. "O tempo não para”, dizem, tornando o passado, mesmo o recente, obsoleto. Eis, porém, que, como um contragolpe a esta escravização das marcações, a aceleração alucinante do tempo marcado estaria fazendo surgir, contemporaneamente, uma subversão progressiva dessas mesmas marcações, com uma tendência ao que François Hartog (2003) chamou de "presentismo", ou nova temporalidade dos jovens, manifestação do surgimento de uma outra marcação (ou desmarcação) da sucessão passado-presente-futuro.

O tempo também varia de sujeito a sujeito. O tempo subjetivo não é aquele do relógio. Este é apaziguador: um segundo, um minuto, uma hora na frente da outra... em uma sequência infinita porém cadenciada, tranquilizadora. Com esse tempo é fácil lidar, é um solo seguro. Mas pouco sentido ele tem para o sujeito. Um deprimido, por exemplo, vivencia o tempo como uma âncora, pesada, difícil de arrastar, encravada no lodo. Para alguém que acabou de se apaixonar, seja por uma pessoa ou uma ideia, o tempo é uma ventania, levando tudo e todos em turbilhão.

O tempo é o tempo de cada um, nunca o tempo de todos. Ele pode, sim, projetar-se como um devir para todos, uma temporalidade que enlaça. Um projeto, um lançamento. Um aqui e agora que institui retroativamente seu passado e nos lança, projetando-nos para um porvir. Esse é um dos tempos possíveis para o sujeito, solo temporal de uma análise, no lugar do tempo regulamentar do relógio.

Nietzsche ([1883-1885] 1983), na voz de Zaratustra, tinha como as três questôes primordiais o tempo, a finitude e a morte. $\mathrm{O}$ grande problema do homem seria o conflito com o seu passado, devendo ser a meta de cada um a afirmação dos acontecimentos. Para Nietzsche, a vida deve ser entendida como uma grande sinfonia, em que nenhuma nota pode ser retirada. Não nos caberia, para o filósofo, ter culpa pelo que passou, pois tudo o que fazemos tem lugar e função na grande obra do que seria a vida de cada um. 
Quando alguém procura uma análise, em geral é porque está em conflito com suas marcas, seu passado. $\mathrm{O}$ passado são as marcas que nos definem. Freud nos disse que as histéricas sofrem de reminiscências. Todo homem é seu sintoma, diria Lacan. E o sintoma nada mais é do que o retorno do passado recalcado.

Devemos lutar contra o tempo? Devemos considerar como impasses as limitaçôes temporais de uma clínica-escola, tentando regulamentá-la além do que o próprio real de seu funcionamento nos impõe?

O tempo de uma análise é o tempo do ato, infrações na sucessão bem comportada do simbólico. A análise de um dia, a análise de dez anos resumem-se ao tempo do ato, que pode se dar em cada sessão, em nenhuma, ou apenas em um momento fugaz de um longo percurso deitado no divã. Cada paciente tem seu tempo, que é também o tempo do seu tempo, o tempo do seu Pai, o tempo de sua urgência.

A clínica-escola tem marcações que lhe são próprias, constrangida que é pelas condições institucionais da qual faz parte. A temporalidade da instituição, no entanto, tende naturalmente a desconhecer as temporalidades que fogem às suas normas e a negligenciar dinâmicas que lhe são estranhas. O "presentismo" dos jovens (Hartog, 2003), por exemplo, assim como o tempo lento dos pobres (Santos, [1989] 2001) nos levam a colocar em questão a lógica da sucessão bem comportada e hierarquizada do sistema. Se não podemos dispensar a instituição, é necessário, no entanto, tentar estar cada vez mais perto das temporalidades de cada paciente. Tentar escutar não apenas as dificuldades que a instituição enfrenta para manter-se em funcionamento, mas estar atento também às dinâmicas próprias do público que a frequenta, dinâmicas estas que, eventualmente, podem tornar até mesmo irrelevantes dificuldades consideradas como impasse pelo olhar marcado da instituição.

\section{REFERÊNCIAS BIBLIOGRÁFICAS}

Badiou, A. (1996). O ser e o evento. Rio de Janeiro: Jorge Zahar. - (1999). Lacan e o real. Conferências de Alain Badiou no Brasil. Belo Horizonte: Autêntica.

Descartes, R. (1649/1983). As paixões da alma. Coleção Os pensadores. São Paulo: Abril. Freud, S. (1893/1974). Caso 4 - Katharina. Obras completas, ESB, v. II. Rio de Janeiro: Imago. (1896/1977). Carta 52. Obras completas, ESB, v. I. Rio de Janeiro: Imago. 
Garcia, C. (2002). Lacan e companhia. Um limite tenso. São Paulo: Editora UNESP.

Granon-Lafont, J. (1990). A topologia de Jacques Lacan. Rio de Janeiro: Jorge Zahar.

Hartog, F. (2003). Des régimes d'historicité-presentisme et expériences du temps. Paris: Seuil.

Lacan, J. (1953-1954/1986). O seminário. Livro I. Rio de Janeiro: Jorge Zahar. . (1963-1964/1985). O seminário. Livro XI. Rio de Janeiro: Jorge Zahar.

. (1966/1998). Escritos. Rio de Janeiro: Jorge Zahar.

Lavendhomme, R. (2001). Lieux du sujet-psychanalyse et mathématique. Paris: Seuil.

Nancy, J.-L. (2003). Das unendliche Ende der Psychoanalyse. L'animal. Littératures, Arts e Philosophies, v. 14/15, 145-151.

Nietzsche, F. (1883-1885/1983). Assim falou Zaratustra. Coleção Os pensadores. São Paulo: Editora Abril.

Santos, M. (1989/2001). O tempo nas cidades. Ciência e Cultura, v. 54, no 2. Disponível em <http://cienciaecultura.bvs.br/scielo.php?pid=S0009-67252002000200020 \&script=sci_arttext\&tlng=>. Acessado em 20/06/2008.

Zizek, S. (2000). Corre, Lola, corre. Acheronta, 12. Disponível em http://acheronta.org/ acheronta12/corre.htm

\section{Notas}

1 Segundo uma das definições que Lacan lhe dá, o final de análise marcaria a passagem de uma percepção de seu próprio mal-estar como resultante de uma incapacidade pessoal (e a consequente sensação de imobilidade e culpabilização) para a constatação de sua finitude constitutiva, abrindo assim a possibilidade de movimentação nas infinitudes singulares que lhe são usufruíveis.

2 Trata-se do filme-documentário Estamira, de Marcos Prado, premiado em diversos festivais de cinema no Brasil e no exterior nos anos de 2004 e 2005. Nele é apresentado o percurso de uma portadora de sofrimento mental, psicótica, de 63 anos, que, conseguindo manter-se à margem da rotina dos dispositivos terapêuticos institucionais, não se deixa cronificar, construindo uma temporalidade própria a partir de sua trajetória de vida como catadora de lixo, por mais de 20 anos, no Aterro Metropolitano de Jardim Gramacho, no estado do Rio de Janeiro. Estamira inventa seu território, do qual ela cuida, vive, retira seu sustento e que se expande em algumas situaçóes, indo além, bem longe, como na cena final, na qual ela, em uma praia, esbraveja seus delírios. Vendo a construção de seu território, de acordo com Célio Garcia (2002), podemos pensar sua doença mental não a partir de uma essência, mas de um acontecido, uma duração em sua trajetória pessoal.

Recebido em 26 de novembro de 2007 Aceito para publicação em 20 de junho de 2008 